\title{
The journey of a COVID-19 patient from admission to recovery and learning to breathe again
}

\author{
Nosheela B Rafique, MBBS, FCPS, Shankar Lal, MBBS, FCPS, Yassir Azzain Mohammed, MD, \\ FCARCSI, Ahmed Ibrahim Aglan, MBChB, MSc, FCARCSI, FRCA, FJFICMI, EDIC, EDRA, EDAIC
}

Correspondence: Dr Nosheela Basit Rafique; E-mail: j.l001@yahoo.com; Phone: +353-899484535 Mobile: 353899484535

\section{Abstract}

Patients with severe COVID-19 may require admission to intensive care unit (ICU). Those who respond successfully to intensive care treatment can be discharged from hospital, but the path to full recovery can still be an odd and lengthy one. We have highlighted here that patients face a lot many challenges even after being cured from the disease.

Key words: COVID-19, recovery; Intensive care; Intensive Care Unit; ICU.

Citation: Rafique N, Lal S, Yassir M, Aglan A. The journey of a COVID-19 patient from admission to recovery and learning to breathe again. Anaesth. pain intensive care 2020;24(5):558-559.

Received: 20 June 2020, Reviewed: 24, 28 June 2020, Accepted: 1 July 2020

\section{Introduction}

Patients diagnosed with COVID-19 may present with mild to severe signs and symptoms ${ }^{1}$ and may require prolonged admission in the intensive care unit. Although anyone can be at risk for severe disease; the one's severely hit are males, elderly, and people with multiple co-morbidities. Out of them who are admitted to intensive care unit (ICU) respond successfully to intensive care treatment and can be discharged from hospital, but the path to full recovery can still be an odd and lengthy one.

We present the case report of our critical patient and wish to highlight the journey of disease and recovery, aiming to give hope and better understanding to those who are battling the COVID-19.

\section{Case description}

The journey of COVID-19 in our 64-year-old female patient started with progressing fatigue and cough for few days at home, on the evidence of no improvement in her signs and symptoms she presented to COVID area of Emergency Department with respiratory distress and high-grade fever. Nasopharyngeal swab for COVID-19 test was taken and subsequently came positive, and there were bilateral multiple infiltrates on her chest X-ray. She had a history of chronic controlled HTN, IDDM, and severe cervical ankylosing spondylitis. Initially, she received care with Noninvasive ventilation but due to ongoing severe hypoxemia and ARDS required intubation and mechanical ventilation. Her inflammatory markers were raised along with raised $\mathrm{CK}, \mathrm{LDH}$, and de-ranged urea and creatinine. She spent nine weeks in the intensive care unit, and her stay was complicated with prolonged mechanical ventilation followed by difficult weaning, renal failure and progressive weight loss. Due to multiple failed attempts of weaning, she required percutaneous dilation tracheostomy. Down the course of the disease, she required continuous renal replacement therapy for a couple of weeks and fortunately recovered from acute renal failure.

Moreover, she received determined physiotherapy, speech and language therapy along with feedback from dietician while recovering from severe disease in ICU. All together helped to communicate with her family from whom she has been away for the last many weeks. Progressively yet gradually she crossed all obstacles along her journey of recovery and was 
discharged to step down later to home walking on her own as "Miracle Lady".

\section{Discussion}

It was a long, arduous journey, for those who managed to win against the COVID-19 virus and liberate from ventilators; the actual rocky phase of life begins now. Many may suffer long-term mental, physical and emotional issues, as per data from their last experience of ICU stay. Most of them suffer from post-traumatic stress disorder (PTSD), cognitive deficits like Alzheimer's, anxiety, depression and economic issues due to job losses. ${ }^{2}$ Furthermore, problems with routine activities like merely taking a shower and selfindependent eating, are faced by them even after several weeks of having left the ICU.

It took her a while before she gained her physical activity back to her baseline. We consider a few crucial steps essential to buffer the adverse effects of the illness i.e. enhancing a sense of security, pacifying social connectedness, self-confidence and hope. She admitted that connectivity with her family has helped her pull through the journey of recovery. In addition to this, she felt a stinging disconnect from her social circle even after having recovered safely.

During her critical condition and multi-organ involvement, we thought of the ceiling her care at various stages. However, surprisingly her condition improved after being treated with a variety of experimental medications, hence was discharged from critical care. Still, her lungs are weak and struggling to recover with a potential risk of infection.

The recovering patients are isolated along with appropriate social distancing SOPs put in place, the majority of rehabilitation centres are closed, and many are not accepting patients recovered from the COVID19. People who survive the illness will likely re-enter the world 'alone' without the usual support of their loved ones due to fear of contagion. This behaviour towards the recovering survivors of this novel disease is unprecedented as it is not the norm.

\section{Conclusion}

Feeding themselves to carrying out simple tasks at home, most of the patients face limitations that they may not have realised in the hospital facility. Many might fear the load of laboured routine lasting many weeks post disease. Also, they are vulnerable to psychological issues on account of being detached from the world for an extended period of time.

It is emphasised that the hospital phase of recovering COVID-19 battle is only halfway down the road. It's an even greater challenge to cope with post-COVID19 care. Therefore, we should address the COVID and post-COVID care with the same level of consideration.

\section{Conflict of interest}

Authors declared no conflict of interest.

\section{Authors' contribution}

RN, LS: Data collection, Manuscript writing YM, MA: Supervision and drafting the final write-up.

\section{References}

1. Lu R, Zhao X, Li J, Niu P, Bo B, Wu H, et al. Genomic characterisation and epidemiology of 2019 novel coronavirus: implications for virus origins and receptor binding. Lancet. 2020;395:565-574. DOI: 10.1016/S0140-6736(20)30251-8

2. Righy C, Rosa RG, da Silva RT, Kochhann R, Migliavaca CB, Robinson CC, et al. Prevalence of posttraumatic stress disorder symptoms in adult critical care survivors: a systematic review and meta-analysis. Crit Care. 2019;23(1):213. [PubMed] DOI: 10.1186/s13054019-2489-3 